\title{
PERANCANGAN REPOSITORY DIGITAL STIKOM TUNAS BANGSA MENGGUNAKAN CODEIGNITER
}

\author{
Willy Hairis Resmantama Silaen ${ }^{1}$, Saifullah², Eka Irawan ${ }^{3}$ \\ ${ }^{1}$ Mahasiswa STIKOM Tunas Bangsa \\ ${ }^{2.3}$ Dosen STIKOM Tunas Bangsa \\ Email: ${ }^{1}$ willyharis.resmantama@gmail.com, ${ }^{2}$ saifullah@ stikomtunasbangsa.ac.id, \\ 3Eka.irawan@amiktunasbangsa.ac.id
}

\begin{abstract}
Abstrak
Penelitian ini bertujuan untuk Perancangan Repository Baru Berbasis Codeigniter. Perangkat lunak ini berfungsi untuk mempermudah proses perancangan Repository. Penelitian ini juga bertujuan untuk mempermudah mahasiswa maupun masyarakat umum untuk mengakses contoh - contoh skripsi mahasiswa Stikom Tunas Bangsa Pematangsiantar. Metode penelitian ini adalah Penelitian dan Pengembangan. Model pengembangan yang digunakan adalah Waterfall yang terdiri dari analisis, desain, implementasi, dan pengujian. Berdasarkan hasil penelitian ini maka dapat diambil kesimpulan yaitu hasil dari pengembangan perangkat lunak adalah berupa Repository Digital Berbasis Codeigniter.
\end{abstract}

Kata Kunci: Repository, Code igniter.

\begin{abstract}
This study aims to design a Codeigniter-Based New Repository. This software serves to simplify the process of designing the repository. This research also aims to facilitate students and the general public to access examples of student thesis at Stikom Tunas Bangsa Pematangsiantar. This research method is Research and Development. The development model used is Waterfall which consists of analysis, design, implementation, and testing. Based on the results of this study, it can be concluded that the results of software development are in the form of Codeigniter-Based Digital Repository.
\end{abstract}

Keywords: Repository, Code igniter.

\section{PENDAHULUAN}

Perubahan teknologi informasi secara global, berpengaruh pada eksistensi Perpustakaan sebagai sistem penyebaran informasi. Perubahan informasi terjadi karena adanya aliran informasi digital melalui media internet. Teknologi digital dapat menerima segala informasi dari gambar, angka, suara, teks, dan audio. Perkembangan tersebut berpengaruh terhadap kebutuhan manusia, yaitu tuntutan memperoleh informasi secara mudah dan cepat. Jika pada awalnya perpustakaan hanya merupakan institusi atau lembaga yang menyimpan dan menyebarluaskan informasi dalam bentuk buku atau kertas, maka perkembangan teknologi menjadikan informasi dalam media kertas berubah dalam bentuk data digital, dan menjadi bagian utama dari Repository atau simpanan kelembagaan. "Repository dapat dipahami sebagai perpustakaan atau suatu lembaga tempat penyimpanan data dalam bentuk digital, Perkembangannya kemudian mengidentikkan Repository sebagai tempat penyimpanan data dalam bentuk digital pada institusi yang biasa disebut perpustakaan digital.” [1]

Perpustakaan STIKOM Tunas Bangsa Pematangsiantar memiliki koleksi terutama berupa karya tulis Mahasiswa yaitu Skripsi namun belum sepenuhnya dapat dimanfaatkan oleh mahasiswa. Oleh Sebab itu Koleksi tersebut harus dibuat dalam format yang mudah diakses.untuk mempermudah akses tersebut maka koleksi tersebut harus dibuat dalam format digital sehingga dapat di akses melalui internet.berdasarkan pengamatan penulis, saat ini di Perpustakaan STIKOM Tunas Bangsa Pematangsiantar belum memiliki akses tersebut. Hal Ini Dilakukan Secara Berkesinambungan Untuk membantu mahasiswa dalam melakukan Penelitian. Manfaat Yang Menjadi Perhatian Utama Bagi Eksistensi Repository Sebuah Perguruan Tinggi adalah untuk Mengumpulkan Skripsi Mahasiswa Dalam Satu Lokasi.

Bila Pengembangan Repository Diterapkan Maka Akan Sangat Berdampak Pada Kemajuan Perpustakaan Digital Kedepannya. Proses Pembangunan Repository Sebaiknya Diterapkan Menggunakan Codeigniter, Agar Lebih Cepat Dalam Prosesnya. Codeigniter Memberikan Kemudahan Dan Kecepatan Dalam Membangun Website. "Codeigniter Memiliki Kelebihan, Salah Satu Kelebihannya Adalah Memiliki Suatu Potongan-Potongan Program Yang Sudah Disusun Untuk Mempermudah Pembuatan Aplikasi Berbasis Web.” [1]. Diharapkan Dengan Adanya Penelitian Ini Dapat Digunakan Sebagai Salah Satu Dasar Menunjang Kemajuan Pendidikan Di Tingkat Perguruan Tinggi.

\section{TEORITIS}

\subsection{Defenisi Repository}

Repository merupakan Penyebaran informasi data digital yang dikelola suatu lembaga perpustakaan melalui media internet yang mana Sumber data digital sendiri didapat dari artikel berupa tulisan skripsi mahasiswa, karya ilmiah dan di input kedalam bentuk elektronik melalui pemindaian[1]

\subsection{Web}


"Web adalah salah satu aplikasi yang berisikan dokumen-dokumen multimedia didalamnya yang menggunakan protokol HTTP (Hypertext Transfer Protocol) dan untuk mengaksesnya menggunakan perangkat lunak yang disebut browser".[2]

\subsection{Database}

“Database merupakan mekanisme pengelolaan data dalam jumlah yang besar secara terstruktur.”[3]

\section{HASIL DAN PEMBAHASAN}

Berdasarkan hasil analisis yang dilakukan penulis dapat disimpulkan bahwa permasalahan yang menjadi dasar yang dilakukan penelitian ini adalah masih banyak hasil Skripsi Mahasiswa, namun belum diintregasikan dalam satu tempat dan tidak dapat diakses di satu tempat. Melalui skripsi ini penulis ingin mengusulkan sebuah Repository yang diharapkan menjadi sebuah jembatan untuk dapat mengintegrasikan data-data yang berbeda itu dalam satu sistem yang sudah ada sebagai pendukung membantu dalam pencarian Contoh Skripsi mahasiswa. Untuk Pembuatan Repository ini penulis menggunakan bahasa pemrograman berbasis Codeigniter. Pada Bab ini penulis akan menjelaskan pembuatan Repository berbasis web.

\subsection{Analisis}

Pada Analisis ini penulis menjelaskan tentang Repository Stikom Tunas Bangsa PematangSiantar yaitu Kebutuhan sistem.

\subsection{Flowchart Perancangan Repository}

Di dalam perancangan ini, ada beberapa tahapan yang harus dilakukan. Tahapan-tahapan tersebut antara lain proses pemilihan Skripsi, yang kedua adalah proses scanning jika referensi yang dipakai masih berupa cetakan. Langkah berikutnya yaitu proses Kelayakan referensi, hal ini dilakukan agar dalam proses pencarian buku digital ini lebih mudah. Kompresi data juga diperhitungkan dalam proses editing referensi di sini. Karena hal ini berpengaruh dalam penyimpanan data. Adapun peracangan ini digambarkan dalam diagram alir seperti yang terlihat pada Gambar 1.

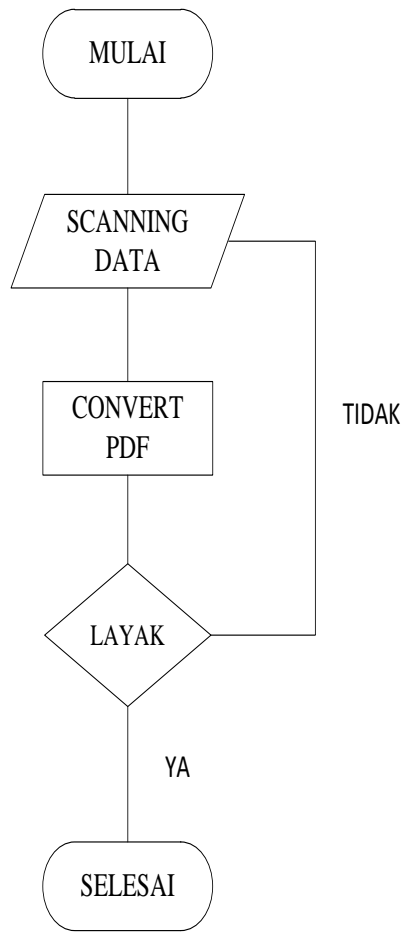

Gambar 1. Flowchart Perancangan Repository

\subsubsection{Flowchart Perancangan Upload File ke Repository}

Kelayakan sebuah referensi merupakan hal yang diperhitungkan. Karena dengan adanya kelayakan referensi tersebut dapat dipergunakan oleh mahasiswa dengan baik, dikarenakan kualitasnya masih terjaga. Pada tahap kelayakan, di sini admin memutuskan referensi manakah yang layak untuk diterbitkan dalam Repository. Adapun peracangan ini digambarkan dalam diagram alir seperti yang terlihat pada Gambar 2. 


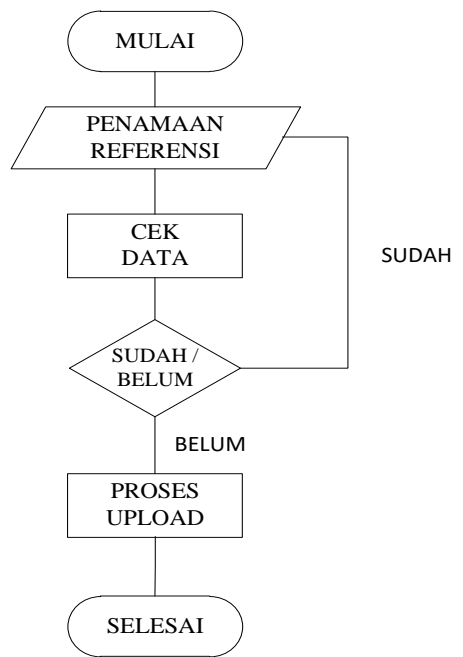

Gambar 2. Flowchart Perancangan Upload

\subsubsection{Analisa Perangkat Lunak}

Dari analisa perangkat lunak dan kemungkinan besar data, maka dapat diperkirakan kapasitas software dan hardware agar perangkat lunak dapat berjalan dengan baik, antara lain sebagai berikut ini:

1. Hanya Memiliki Satu domain

2. satu unit server yang terpasang webserver Apache, $P H P$, dan database $M y S Q L$;

3. untuk pengguna harus memiliki koneksi internet.

4. Agar memudahkan dalam perawatan, maka server yang digunakan adalah berupa web hosting yang disewa dari Penyedia jasa web hosting seperti hostinger.

\subsubsection{Perancangan User Interface}

Secara garis besar, antar muka pada sistem informasi ini terbagi menjadi tiga bagian, antara lain: Halaman Login, Halaman Admin, dan Halaman Utama. Dari ketiga bagian ini selanjutnya dikembangkan untuk menjadi halaman lain sesuai kebutuhan.

1. Halaman Login

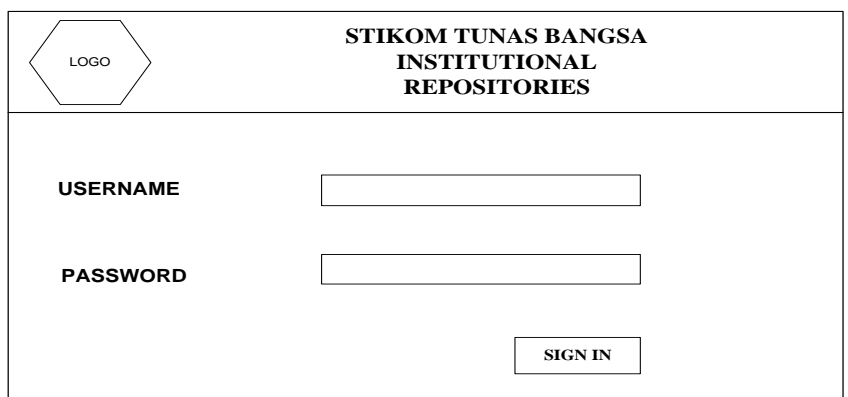

Gambar 3. Desain halaman Login

Gambar 3 menjelaskan rancangan halaman login. Terdapat dua buah form untuk memasukan username dan password serta terdapat satu buah tombol sign in untuk mengirim data.

2. Halaman Admin

\begin{tabular}{|c|c|}
\hline REPOSITORY & \\
\hline MENU & DASHBOARD \\
MENU & \\
MENU & \\
& \\
& \\
\hline & \\
\hline
\end{tabular}

Gambar 4. Desain Halaman Admin 
Gambar 4 menjelaskan rancangan halaman untuk admin. Setiap bagian akan dipecah lagi ke dalam bagian-bagian yang lebih kecil, antara lain: header, sidebar, notice, isi, dan footer. Untuk header, sidebar, notice, dan footer dapat digunakan secara berulang kali, selanjutnya hanya tinggal membuat bagian isi. Pada bagian kiri terdapat navigasi.

3. Halaman Utama

\begin{tabular}{|l|l|}
\hline Logo & MENU MENU \\
\hline Recently add & \\
& \\
\hline
\end{tabular}

Gambar 5. Desain Menu Utama

Gambar 5. menjelaskan rancangan halaman untuk Umum. pada bagian atas terdapat menu untuk navigasi. Halaman ini juga dipecah menjadi header, sidebar, notice, dan footer yang dapat dipanggil berkali-kali, selanjutnya adalah bagian isi.

\subsubsection{Perancangan Database}

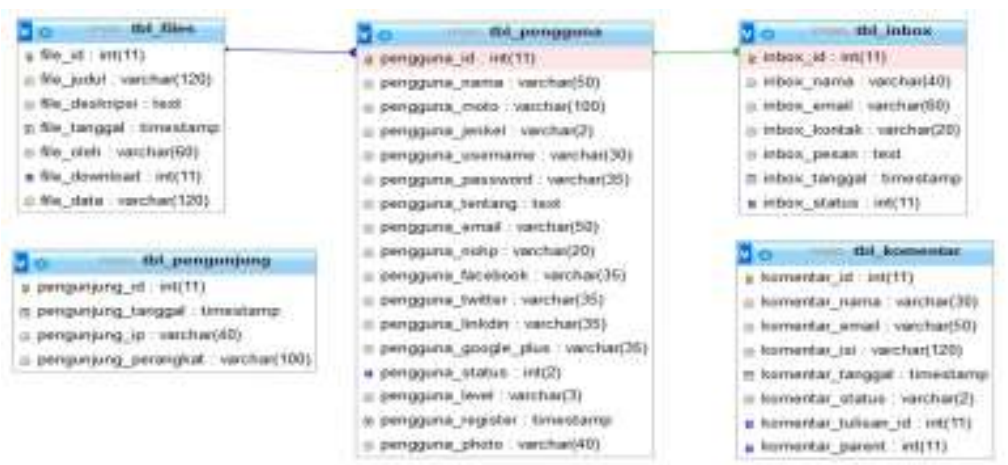

Gambar 6. Perancangan Database

Terdapat Lima tabel pada rancangan database, antara lain sebagai berikut: tabel Pengguna, tabel files, tabel Inbox, tabel pengunjung, dan tabel komentar.

\subsection{Implementasi MVC ( Models View Controler)}

Implementasi $M V C$ merupakan tahap saat pembuatan aplikasi dimulai. Rancangan program yang telah disiapkan kemudian diterjemahkan dalam bahasa pemrograman, sehingga semua fungsi dapat berjalan dengan baik sesuai kebutuhan pengguna. Tahap implementasi meliputi Models, view serta Controler.

\subsubsection{Models}

Implementasi ini merupakan bagian bahasa pemrograman untuk operasi Create, Read, Update, dan Delete (CRUD) data. Models terdapat di dalam folder C://xampp/htdocs/Nama file/Application/Models

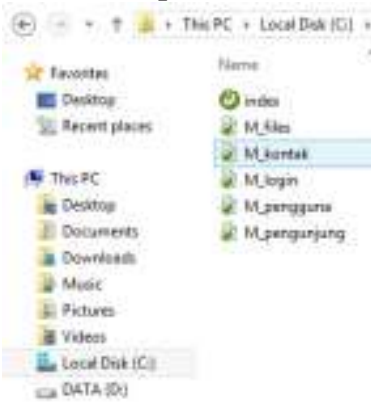

Gambar 7. Implementasi Models

1. View

View berisikan kode program untuk designer html, css, dan js karena code-code di bagian ini untuk menampilkan tampilan web yang menarik dan interaktif. View terbagi dua yaitu View Admin dan View 
beranda.

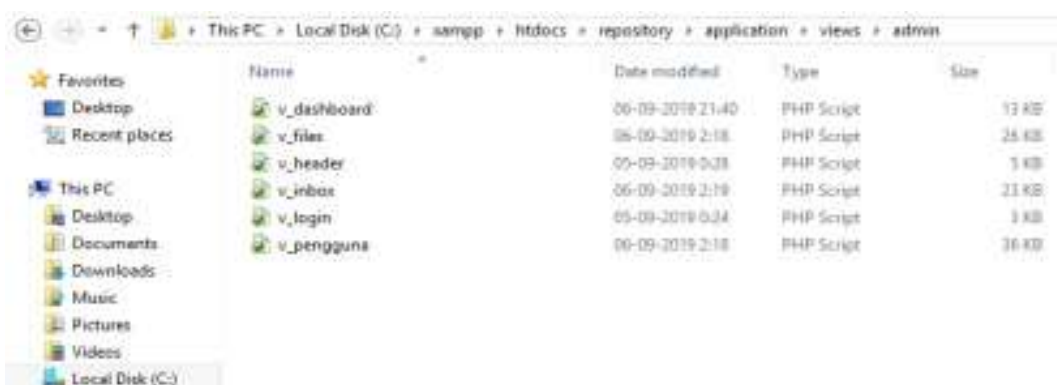

Gambar 8. Implementasi View Admin

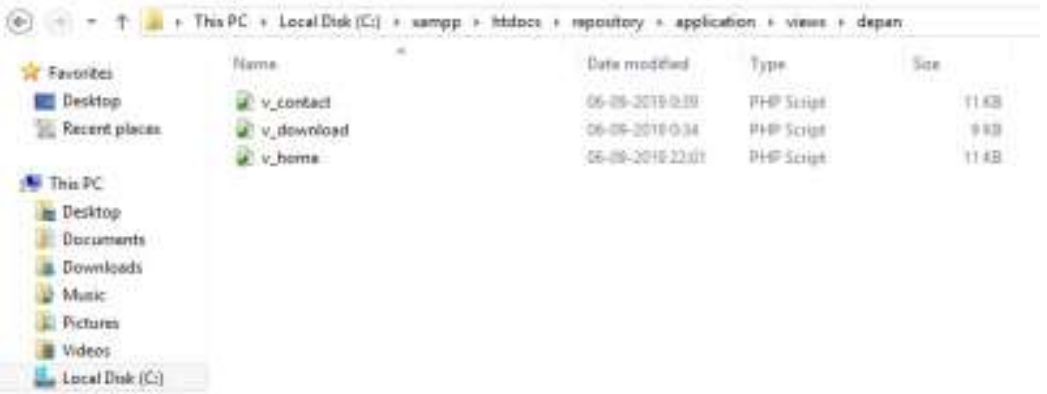

Gambar 9. Implementasi View Beranda

2. Controller

Controller berisikan kode Program yang menjadi penghubung Model dengan View. Controller terdapat di dalam folder C://xampp/htdocs/Nama file/Application/Controller

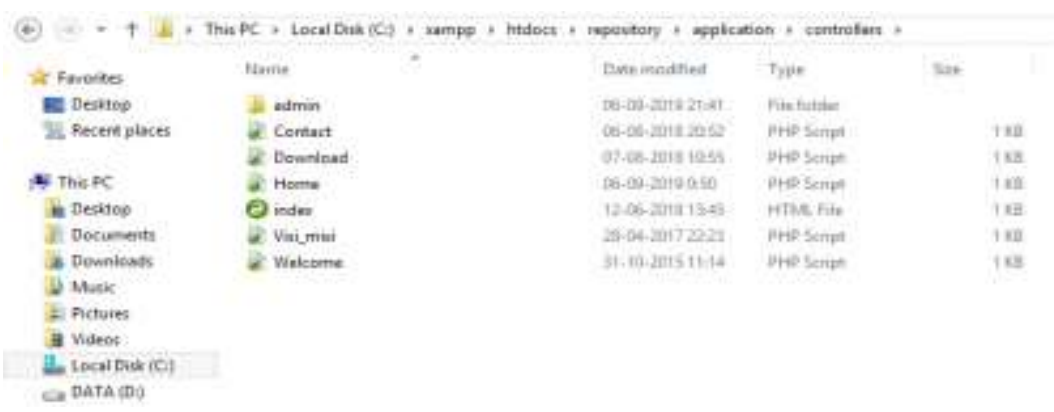

Gambar 10. Implementasi Controller

\subsection{Implementasi Interface (Antar Muka)}

Dalam bagian ini menjelaskan beberapa hal yang berhubungan dengan bagaimana cara penggunaan Repository di Stikom Tunas Bangsa Pematangsiantar.

1. Halaman Beranda Repository Stikom Tunas Bangsa Pematangsiantar

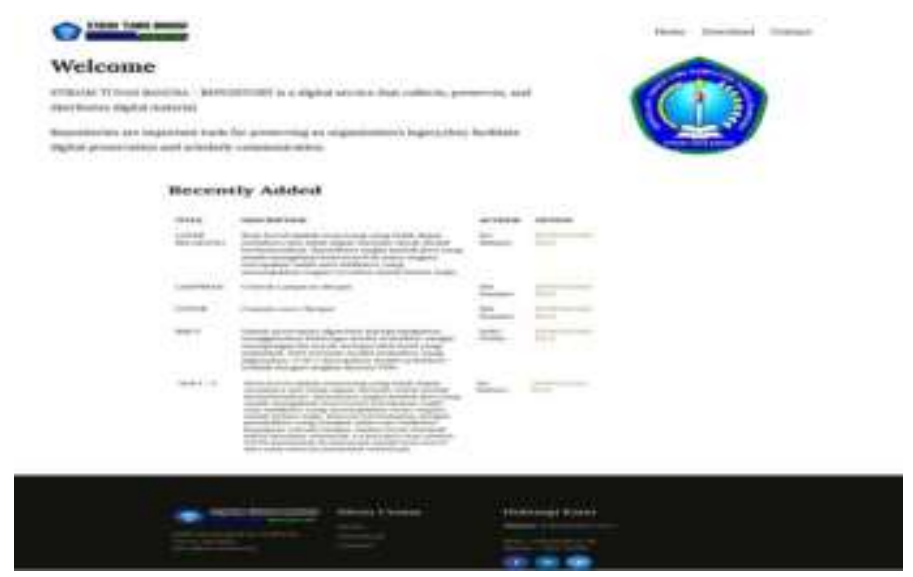

Gambar 11. Tampilan Beranda Repository 
Pada gambar di atas merupakan halaman utama dari Repository Stikom Tunas Bangsa Pematangsiantar. Pada Repository tersebut memiliki beberapa menu navigasi yaitu menu Home, Download, dan Contact.

2. Halaman Download

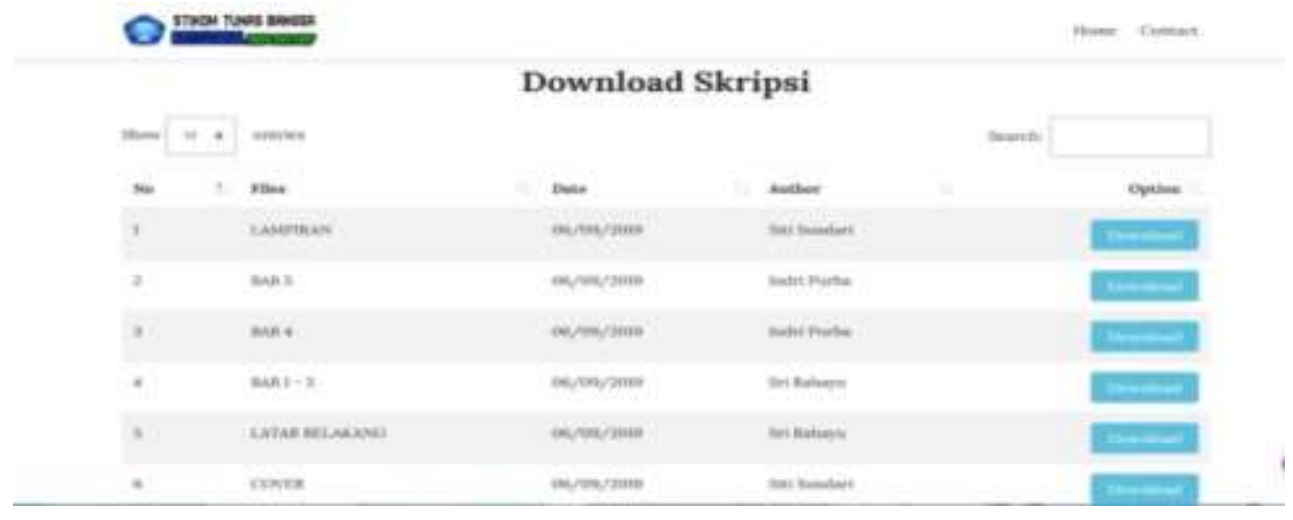

Gambar 12. Tampilan Download file

Pada Halaman Download tersebut memiliki beberapa referensi Skripsi Mahasiswa yang dapat didownload.

3. Halaman Contact

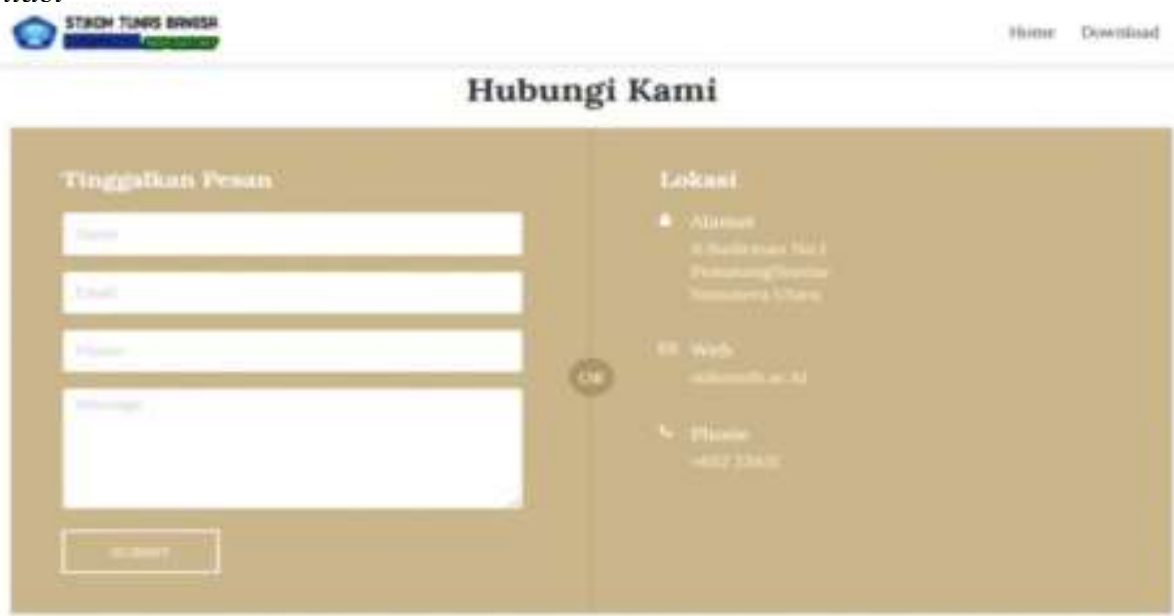

Gambar 13. Tampilan menu contact

Pada Halaman Contact tersebut memiliki beberapa isian kolom yang berfungsi memberi komentar atau masukan ke pihak pengelola Repository.

4. Halaman Login Administrator

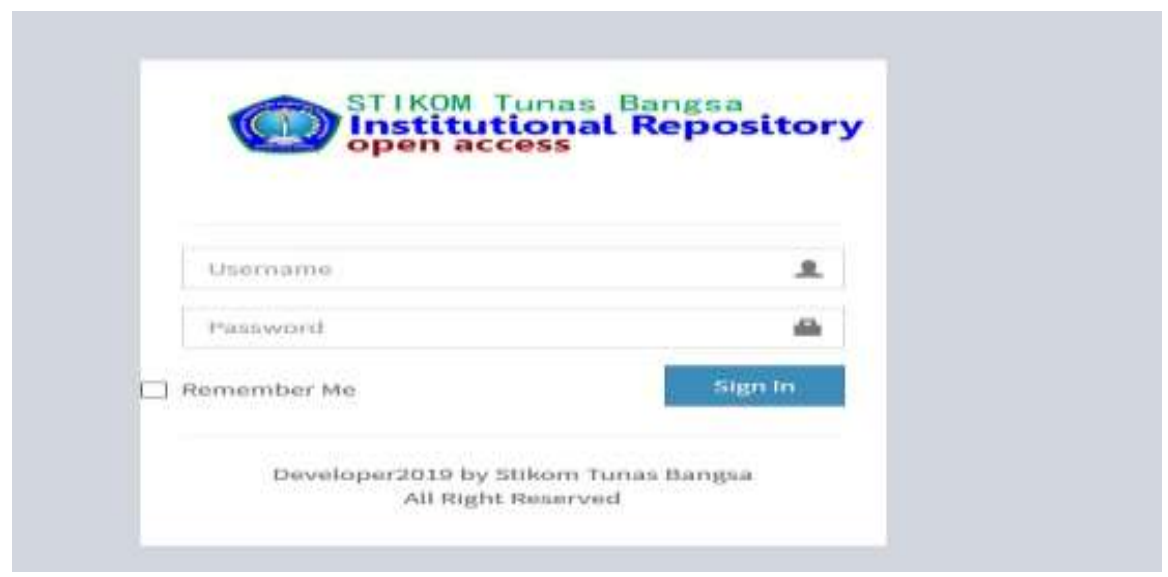

Gambar 14. Halaman Login

Admin Harus melaukan login dengan menginput username dan password yang telah terdaftar di dalam sistem Repository Stikom Tunas Bangsa untuk dapat melakukan upload file.

5. Halaman Dashboard Administrator 


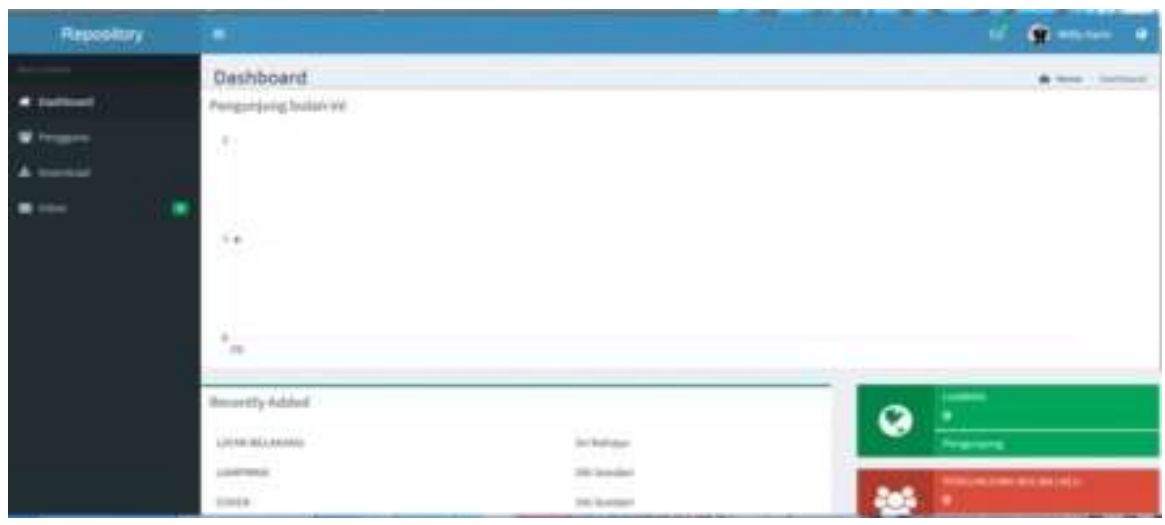

Gambar 15. Halaman Dashboard Admin

Setelah Admin melaukan login dengan menginput username dan password yang telah terdaftar di dalam sistem Repository Stikom Tunas Bangsa maka halaman awal yang akan tampil seperti gambar 15

6. Halaman User Pengguna

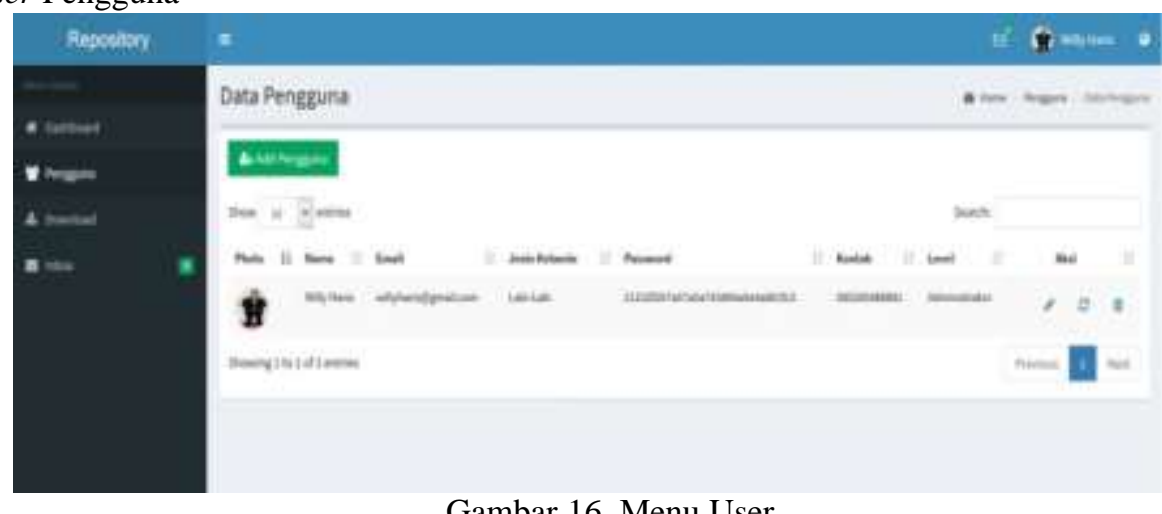

Pada Menu Pengguna, akan menampilkan data user yang dapat Login ke Halaman Dashboard Admin.

7. Halaman Add User Pengguna
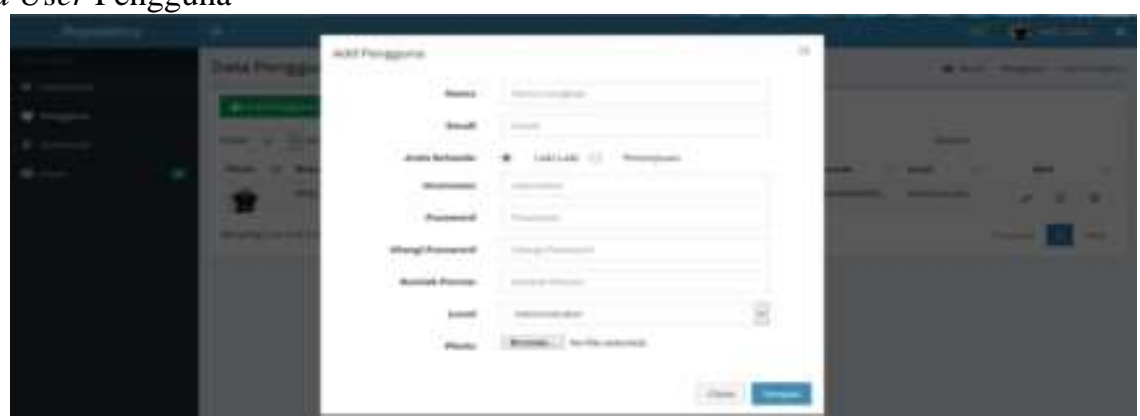

Gambar 17. Add User

Pada gambar 17. menampilkan menu menambah pengguna (user) baru, dengan mengisi kolom yang telah disediakan.

8. Halaman Edit User

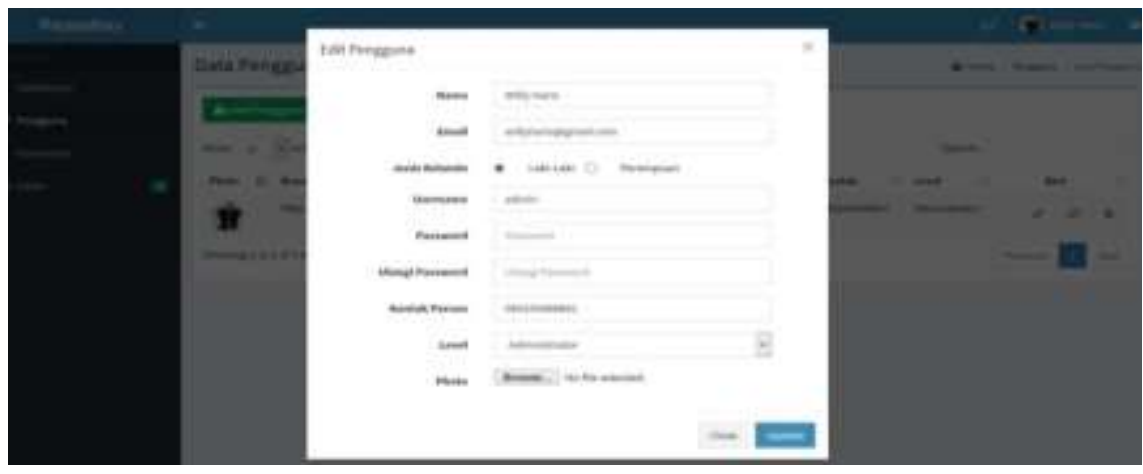

Gambar 18. Edit user 
Pada gambar 18. menampilkan halaman untuk mengedit data pengguna (user) yang telah tersimpan di database.

9. Halaman Download

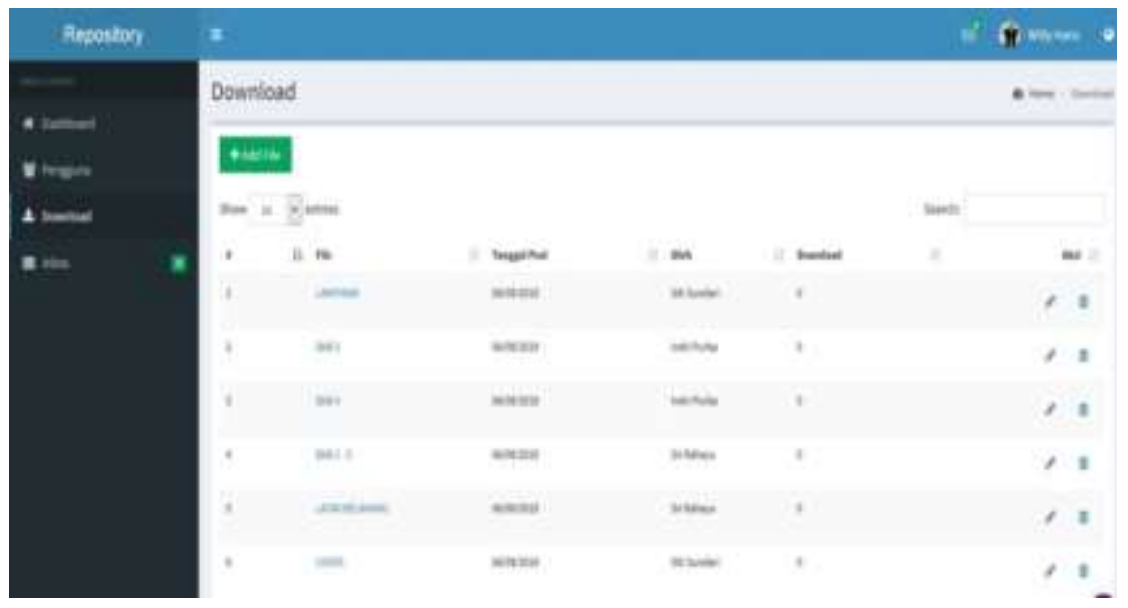

Gambar 19. Menu File Download

Pada gambar 19. menampilkan halaman File atau data referensi dalam bentuk PDF yang telah di Upload Ke database Repository.

10. Halaman Add Download

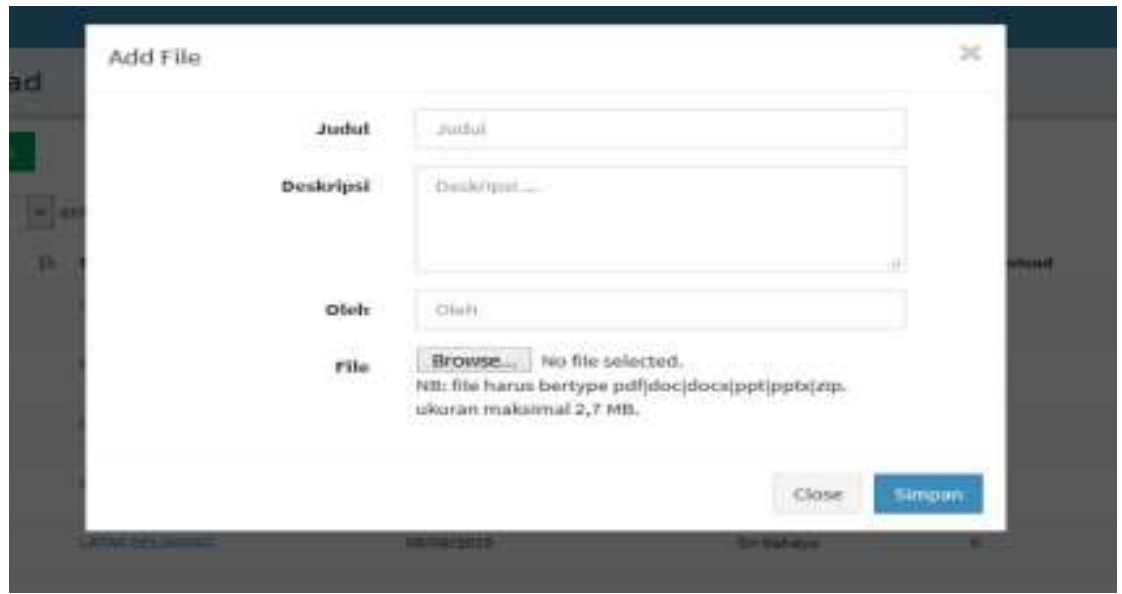

Gambar 20. Add File

Pada gambar 20. menampilkan menu untuk Mengupload File pdf ke dalam system Repository. 11. Halaman Edit Download

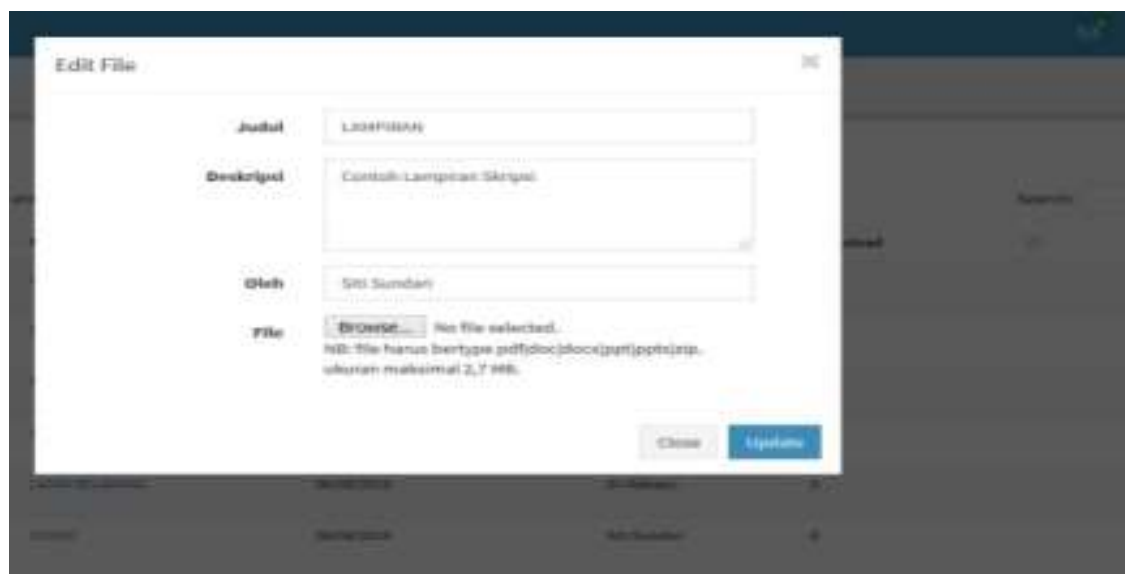

Gambar 21. Edit file

Pada gambar 21. menampilkan halaman untuk mengedit informasi File yang telah di Upload dan yang sudah tersimpan di database.

12. Halaman Inbox Komentar 


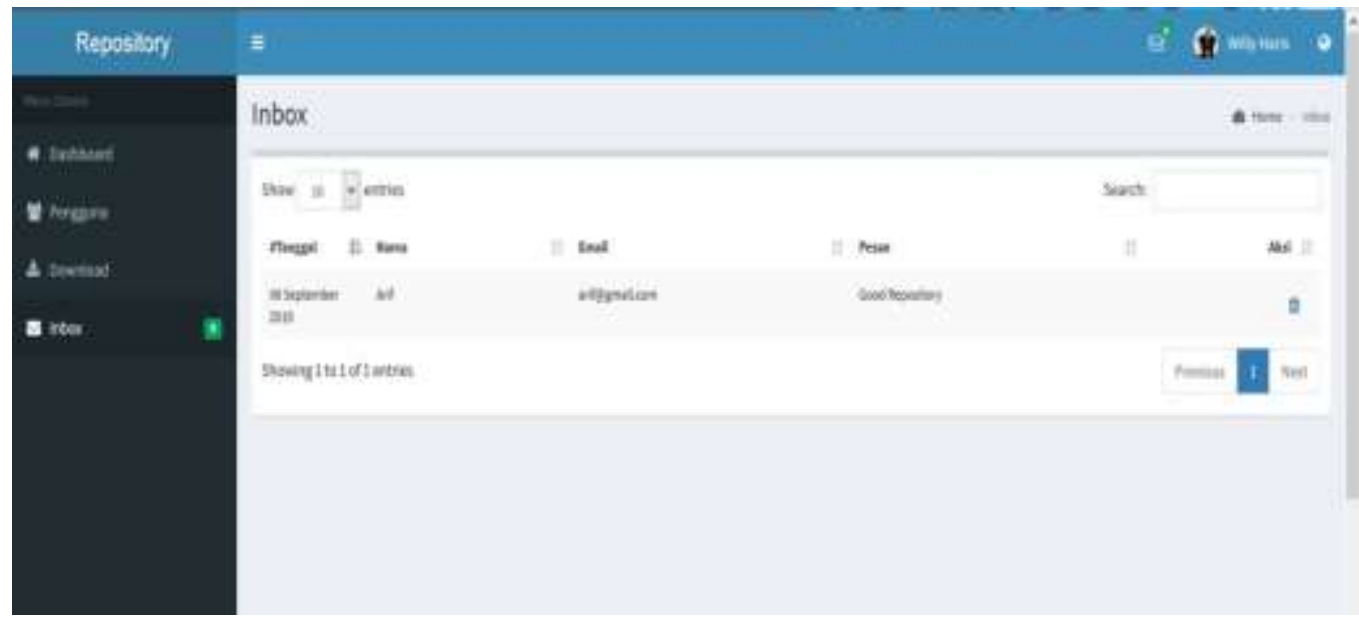

Gambar 22. Inbox

Pada gambar 22. menampilkan halaman Inbox atau halaman yang berisi Komentar dari setiap Pengunjung.

\subsection{Pembahasan}

Berdasarkan dari penjelasan diatas mengenai Perancangan Repository Stikom Tunas Bangsa Pematangsiantar, Repository Tersebut Memiliki Kelebihan Dan Kekurangan, diantaranya yaitu:

\subsubsection{Kelebihan Repository Stikom Tunas Bangsa Pematangsiantar}

Adapun kelebihan-kelebihan Repository STIKOM Tunas Bangsa Pematangsiantar adalah sebagi berikut :

1. Repository STIKOM Tunas Bangsa memberikan kemudahan bagi mahasiswa untuk melakukan pencarian Koleksi Skripsi.

2. Layanan akses Bersifat Online.

3. Memberikan referensi bagi mahasiswa dibidang penelititan.

\subsubsection{Kekurangan Repository Stikom Tunas Bangsa Pematangsiantar}

Berdasarkan kelebihan-kelebihan yang telah dibahas di atas, tentunya Repository Stikom Tunas Bangsa mempunyai beberapa kekurangan tersebut adalah:

1. Tampilan halaman utama Repository STIKOM Tunas Bangsa masih sederhana karena hanya untuk membantu memberikan referensi tentang Skripsi Mahasiswa.

2. Tidak tersedianya menu download buku digital bagi mahasiswa, Karena Hanya Menyimpan Dan Menampilkan Koleksi Skripsi Mahasiswa STIKOM Tunas Bangsa Pematangsiantar.

\section{KESIMPULAN}

Berdasarkan hasil dan pembahasan sebelumnya kesimpulan dari skripsi ini sebagai berikut :

1. Repository STIKOM Tunas Bangsa Pematangsiantar dapat menjadi suatu layanan akses buat mahasiswa ataupun Kalangan Umum dalam membantu pencarian referensi mahasiswa dalam proses penelitian.

2. Dengan Adanya Repository STIKOM Tunas Bangsa Pematangsiantar Koleksi Skripsi Mahasiswa STIKOM Tunas Bangsa dapat diakses secara online.

\section{REFERENCES}

[1] G. A. Sandag, A. T. Liem, M. P. Matauseya, and G. Wantah, "Digital Library Jurnal dan Artikel Dengan Modul Automatic Citation Format Berbasis Web," CogITo Smart J., vol. 3, no. 2, p. 196, 2017.

[2] T. Listyorini and M. Iqbal, "Perancangan Pengembangan Digital Library Berbasis Web Responsive," Simetris J. Tek. Mesin, Elektro dan Ilmu Komput., vol. 6, no. 1, p. 69, 2015.

[3] Gat, "Perancangan Basis Data Perputakaan Sekolah dengan Menerapkan Model Data Relasional," Citec, vol. 2, No. 4, pp. 304-315, 2015. 